EVS28

KINTEX, Korea, May 3-6, 2015

\title{
Development of a new concept electric vehicle for last mile transportations
}

\author{
L. Andaloro, G. Napoli, F. Sergi, S. Micari, G. Agnello, V. Antonucci \\ National Research Council of Italy - CNR \\ Institute of Advanced Technologies for Energy "Nicola Giordano"- ITAE \\ Salita S. Lucia sopra Contesse, 5 - 98126 Messina, Italy
}

\begin{abstract}
Within European cities, where $68 \%$ of the EU population lives using $70 \%$ of the energy, an integrated and sustainable urban approach is needed. In order to meet the increasingly complex challenges of urban areas new, efficient, and user-friendly technologies and services, in particular in areas of energy, transport, and ICT are required.

In the transport sector electric urban mobility and synergy between different transport systems (ITS) and infrastructures must be supported strongly in order to improve life conditions of citizens in terms of i) emissions, ii) services, iii) traffic congestion (an ambitious challenge is reduction of journey times). With the aim of improving the city logistic more efficient peopletransport and freight-distribution systems have to be used, so electro-mobility for transport in the "last mile" must be supported.
\end{abstract}

In the i-NEXT (Innovation for greeN Energy and eXchange in Transportation) project, in which CNR ITAE is directly involved as coordinator, activities are addressed to implementation of new concept modular electric vehicles having different upper-bodies able to be used both for people (public transport) and freight in urban areas. The project aims to develop a not commercial vehicle characterized by new design in which the challenge is to reach the lowest ratio between total weight and load capacity (europallet for freight and seats for people).

Other important aspects are to define specific mission of use, range of autonomy, recharge times and cost in terms of batteries and recharge systems technologies.

In conclusion synergy of electro-mobility with renewable energy plants and smart grids is essential for sustainability of smart city concept.

Keywords_Last mile; Electric Vehicle (EV); Urban mobility;

\section{Introduction}

In a growing economy, the urban freight transport becomes increasingly important.
Concerns about environmental problems as urban air quality and global climate change have increased attention on renewable energies. However, the freight sector has been generated inefficiencies on social and economic aspects 
although there are numerous opportunities for energy reductions. A possible solution is the use of Urban Distribution Centres (UDCs) of goods in order to rationalise the deliveries, use of zeroemission vehicles for the last miles distribution and use of intelligent transport systems. It would contribute to real-time traffic management, reducing delivery times and congestion last mile as described in the "White Paper" by European Commission [1]. The aims of this work is the development of a new concept electric vehicle for last mile transportations. The experimental phase will be carried out in Sicily (Italy), and, specifically in Capo d'Orlando Municipality.

In the last years many studies have been in order to solve last-mile delivery issues. Multi-Criteria Decision based on Fuzzy theory for UDC localization has been developed in [2] based on several criteria as urban congestion, air quality and reduction of the total distribution cost in order to increase business efficiency. A profitmaximizing auction mechanism for the consolidation of shipments into the city centre for the last-mile deliveries via Urban Consolidation Centres (UCC) has been proposed in [3]. Such auction is aimed to achieving both operational viability and economic efficiency for the sustainability of the UCC. Taking into account the restrictions that are more and more frequently imposed on freight vehicles traffic, as well as taxes and fees charged by local self-governments a study on the possibilities of applying electrically powered vehicles in urban freight transport has been studied in [4]. This may contribute to reduce the delivery costs in cities, which may account up to $40 \%$ of total transport costs. An Electric Vehicles for urban logistics improvement has been proposed in [5]. The project, according to the European Union action plan on urban mobility, aims to support innovation in transportation, by promoting a system based on sustainable mobility and Renewable Energy Sources (RES). At the same time, by acting on improving logistics and on distribution channels, it will offer promising opportunities for enhance urban logistics and to ensure more environmentally sustainable.

In this work a development of a new concept electric vehicle for last mile transportations is reported. The goal is to define and develop a new class of zero-emission vehicles in order to build a leading position in the implementation of electrical solutions in the field for last-mile urban centres. It is divided in five sections. The first one shows a general introduction about the problem of last mile delivery. Section two describes the territory of Capo d'Orlando and third section the innovative vehicle features. Technical specifications vehicle have been done in section four and the main conclusions and discussions have been described in the final section.

\section{Testing area}

Capo d'Orlando is a municipality located 150 $\mathrm{km}$ from Palermo and $100 \mathrm{~km}$ from Messina; with both is connected by S.S. 113, by A20 highway and by railway line. The administrative territory has an area of $14.56 \mathrm{kmq}$ and consists of a coastal strip sub-hill sloping down to the Tyrrhenian Sea. The coast, with the Aeolian Islands in front, is about $12 \mathrm{~km}$ and is a well-known as summer tourist destination. It is a major demographic attraction and occupational centre in the Nebrodi area.

In Capo d'Orlando city an integrated plant (composed by systems for electric mobility, energy production from RES, energy saving, and energy storage) will be realized by CNR ITAE, directly involved in the project as coordinator, and by other partners. It aims to support innovation in transport by promoting a system based on sustainable mobility and RES in order to improve logistics and distribution channels. These actions will allow to guarantee an energy supply safety and a consequent decrease of energy costs. The UDC will be localized in ctr. Masseria as shown in Figure 1 and will include a photovoltaic generator, an energy storage system, system for production, compression and storage of hydrogen, electric and hydrogen charging stations and a system of monitoring and control as shown in Figure 2.

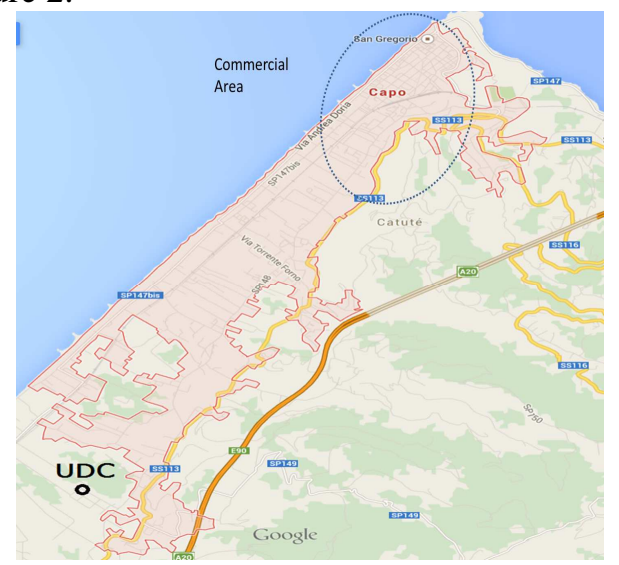

Figure 1: Capo d'Orlando Municipalities - UDC Contrada Masseria $38^{\circ} 07^{\prime} 16,15^{\prime}$ N $, 14^{\circ} 42^{\prime} 58,01^{\prime}$ E 


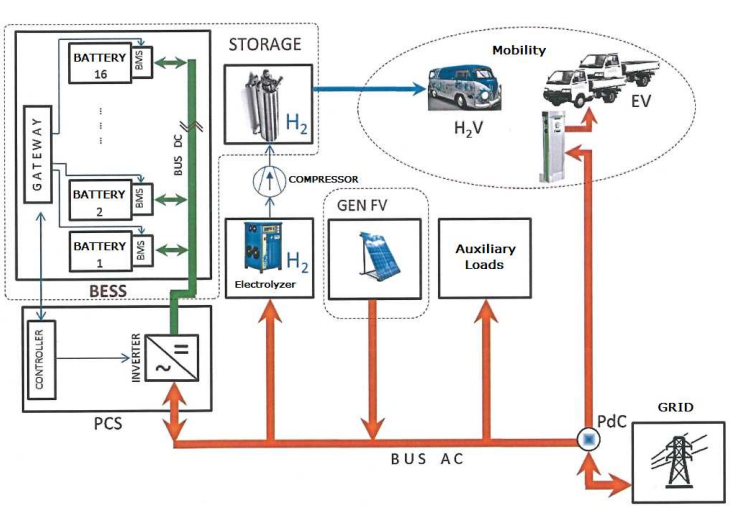

Figure 2: Energy Production System

\section{Innovative vehicle features}

The proposed vehicle presents innovative and structural characteristics as: a rolling and flexible chassis which allows the integration with different electric propulsion systems (EPS), the possibility to install different upper body, a greater payload than vehicles in the same category, a new multifunctional cabin with innovative style, a mobile platform in order to facilitate the loading and unloading of goods and a info mobility system in order to collect, process and transmit the positioning and operational data of the vehicle to a service centre.

The rolling chassis has been projected to contain the powertrain using recyclable and lightweight materials and it has been made with space frame technologies with aluminium extrusion components and appropriate connecting elements. It guarantees high levels of impact protection, in particular for the battery pack, the driver and the passengers. The steering wheel has been anchored to the bottom part of the chassis in order to carrying out an integrated structure that contributes to the safety of the passengers. The platform architecture allows the correct installation, for different size, of the traction elements and energy storage as a function of its specific mission of use. The resulting weight distribution with a low centre of gravity will allow to have a flat floor without requiring the creation of a monocoque body. The suspensions depend on the characteristics of the electric traction.

The different upper body as glazed van, cabin cruiser, van and box van allows to have a greater carload and a ratio between carload and kerb weight (RC) greater than similar EV currently on sale. The volume of load allows to contain two Euro pallet $(1200 \times 800 \mathrm{~mm})$.

The vehicle will have an innovative design and a large windshield, with an high ratio between total glass surface and total cabin surface (RV) that it allows better driving conditions. The cabin is also equipped with an info-mobility systems.

In conclusion, particular attention has been given to the production process for low volume production using low-cost technology investments.

\section{Technical specifications vehicle}

The new concept of electric vehicle for last mile transportations in N1 category (under European Directive 2007/46/CE) has been implemented under the technical characteristics of CNR ITAE reported in Table 1:

Table 1: vehicle characteristics

\begin{tabular}{|c|c|}
\hline max vehicle length: & $5 \mathrm{~m}$ \\
\hline max vehicle width: & $2 \mathrm{~m}$ \\
\hline $\begin{array}{l}\text { max vehicle laden } \\
\text { mass: }\end{array}$ & $2.5 \mathrm{t}$ \\
\hline min vehicle carload: & $800 \mathrm{~kg}$ \\
\hline load volume vehicle: & $\begin{array}{l}2 \text { euro pallet }(1200 \mathrm{x} \\
800 \mathrm{~mm})\end{array}$ \\
\hline $\min \mathrm{RC}:$ & 0,6 \\
\hline $\min \mathrm{RV}:$ & 0,147 \\
\hline max chassis weight: & $400 \mathrm{~kg}$ \\
\hline min motor efficiency & $90 \%$ \\
\hline motor nominal power: & $45 \mathrm{~kW}$ \\
\hline motor Peak power: & $70 \mathrm{~kW}$ \\
\hline $\begin{array}{l}\text { min AC power } \\
\text { recharge system: }\end{array}$ & Modo 3, IEC 61851-1 \\
\hline $\begin{array}{l}\text { min DC power } \\
\text { recharge system: }\end{array}$ & $\begin{array}{c}\text { Modo } 4 \text { 22kW, IEC } \\
61851-1\end{array}$ \\
\hline \multirow[b]{2}{*}{ connector: } & 3c type IEC 62196-2 \\
\hline & $\begin{array}{c}\text { Combo Connector } \\
\text { (Combo 2, SAE J1772) }\end{array}$ \\
\hline min vehicle speed: & $80 \mathrm{~km} / \mathrm{h}$ \\
\hline min vehicle autonomy: & $100 \mathrm{~km}$ \\
\hline Max gradeability: & $18 \%$ \\
\hline max cargo bed width: & $1500 \mathrm{~mm}$ \\
\hline max cargo bed length: & $2500 \mathrm{~mm}$ \\
\hline
\end{tabular}

\subsection{Powertrain}

Among several available energy sources for the constitution of the power train, an electric propulsion system has been selected.

The electric engine typology which has been chosen for the traction is an Interior Permanent Magnet (IPM), subclass of the category of permanent magnet motors. IPM engines use a higher number of magnets than the surface mounted PM motors but they have an extended 
speed range with constant power operation over surface PM motors [6].

In fact, evaluating all the available commutatorless engines, only permanent magnet brushless motors have the capability to compete against the induction motors in vehicle propulsion system [6]. This option involves several advantages in comparison with other engine typologies (Figure 3):

- It's possible to have a wide field of engine speeds in which the output power can be kept constant, with a reduced inverter sizing;

- In short circuit and overcharge conditions, interior magnets don't risk to be demagnetized;

- PMs excite the field which offers high power density, reduced weight and volume for given power rating;

- It offers highly efficient operation;

- Compact packaging provides higher degree of reliability and maintenance free operation;

- Effective dissipation of heat into atmosphere enables efficient cooling.

\begin{tabular}{|c|c|c|c|c|}
\hline \multirow[t]{2}{*}{ Characteristic } & \multirow{2}{*}{$\begin{array}{l}\text { Motors with } \\
\text { commutator }\end{array}$} & \multicolumn{3}{|c|}{ Motors without commutator } \\
\hline & & $\begin{array}{l}\text { Induction } \\
\text { motor }\end{array}$ & $\begin{array}{l}\text { PM } \\
\text { motor }\end{array}$ & $\begin{array}{l}\text { SR } \\
\text { motor }\end{array}$ \\
\hline Controllability & 5 & 5 & 4 & 3 \\
\hline Size and weight & 3 & 4 & 4.5 & 4 \\
\hline Robustness & 3.5 & 5 & 4 & 4.5 \\
\hline Reliability & 3 & 5 & 4 & 4.5 \\
\hline Power density & 3 & 4 & 5 & 3.5 \\
\hline Efficiency & 3 & 4 & 5 & 4.5 \\
\hline Speed range & 2.5 & 4 & 5 & 5 \\
\hline Life time & 3.5 & 5 & 4 & 4.5 \\
\hline Torque density & 3 & 3.5 & 5 & 4 \\
\hline Technical maturity & 5 & 4.5 & 4 & 3.5 \\
\hline Cost & 3.5 & 5 & 3 & 4 \\
\hline Over load capability & 3 & 4 & 4.5 & 4 \\
\hline Torque ripple/noise & 3.5 & 4.5 & 4 & 3 \\
\hline Manufacturability & 3 & 5 & 3 & 4 \\
\hline $\begin{array}{l}\text { Potential for } \\
\text { improvement }\end{array}$ & 2.5 & 3 & 4.5 & 5 \\
\hline
\end{tabular}

Figure 3: Comparative analysis of different Electric Motors used in electric propulsion system [6]

In particular, the proposal solution shows a "four layers" rotor, four flow barriers per pole. Each layer is partially filled with high energy density magnets $(\mathrm{NdFeB})$. The stator has also a high number of slots (48 slots on a 2 pole pairs). The high number of layers of the rotor and an appropriate number of stator slots reduces iron losses. These characteristics make it particularly suitable for automotive applications because it cover the entire field of motor speed without the use of a mechanized gearbox as shown in Figure 4.

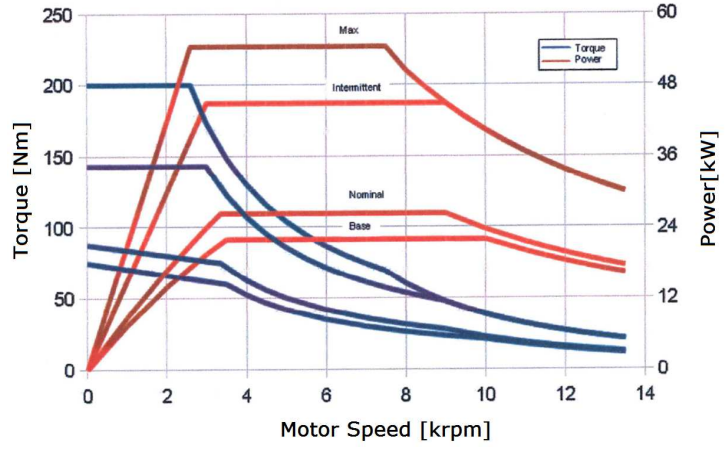

Figure 4 - Theoretic Motor Speed vs. Torque/Power features of electric engine

The numerous bench tests showed high correlation between the expected characteristics and the experimental evidence as shown in Figure 5 .

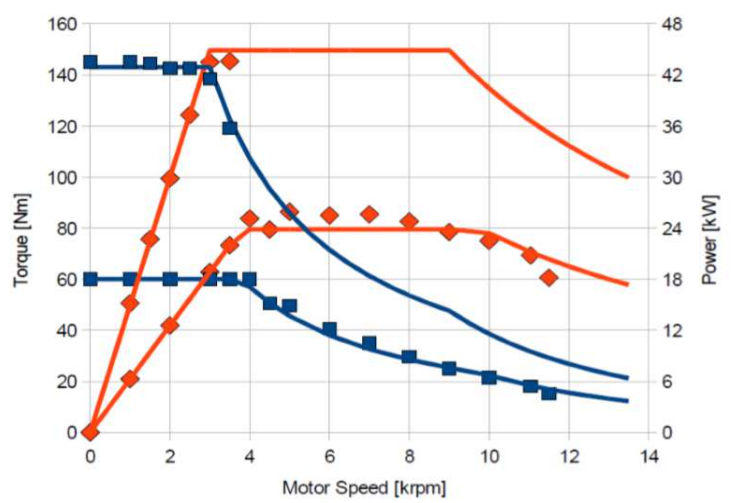

Figure 5: Experimental characterization engine

The modular construction allows to obtain high scalability with a limited number of construction elements. The choice of the number of modules and of the relative power will be decided after the first phase of the project.

\subsection{Control unit}

The electronic control unit (Figure 6 and Figure 7) is based on a Digital Signal Processor (floating point), on which has been implemented a highly structured code at different levels:

- Operating system (hard real-time);

- Code Drive (Universal Direct Drive Vector Control);

- "User" part that is dedicated to specific application (Traction Manager). 


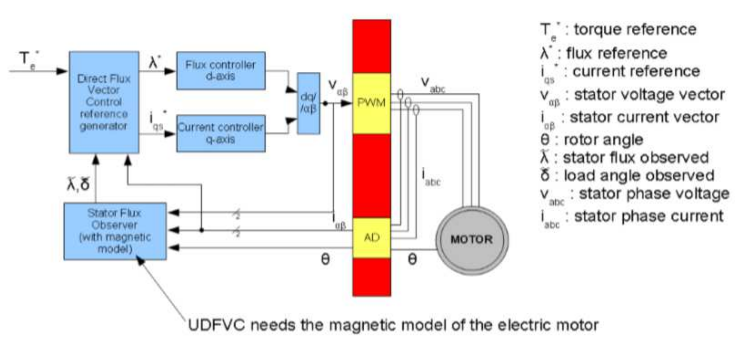

Figure 6 - Block diagram of electric control unit

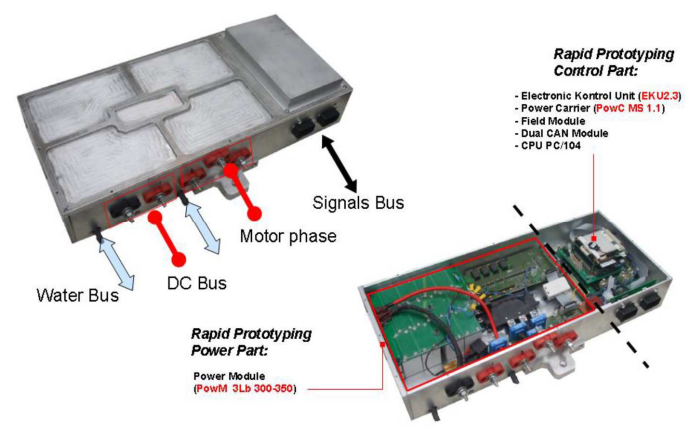

Figure 7 - Electronic control unit

\subsection{Chassis \& Body}

The project aims to provide a vehicle with a high modularity from the point of view of the structure. The main aspect of the architecture is the separation between the lower part (mechanized chassis within powertrain, brakes and suspension) and the upper part (body) of the structure. The chassis is carried out by the use of aluminum extrusions and specific connection elements. The latter has been obtained by melting and molding in order to guarantee high rigidity at the whole structure as shown in Figure 8 and Figure 9.

This architecture allows the following characteristics:

- Modularity of the chassis dimensions for wheelbase and wheel track;

- Adaptability for different upper body vehicle solutions as glazed van, cabin cruiser, van, box van;

- Adaptability for different powertrain architectures;

- lower productive investment;

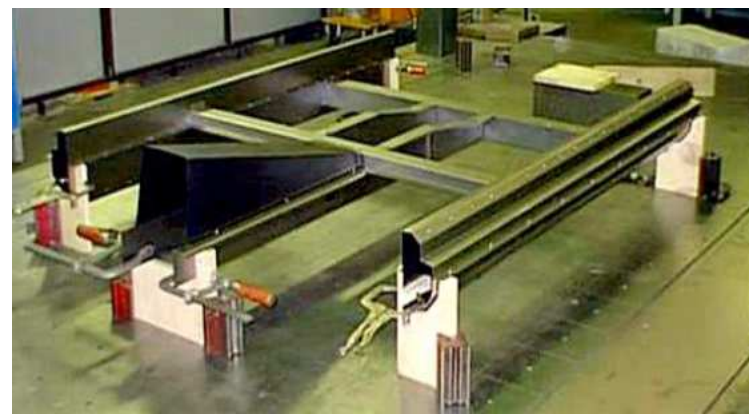

Figure 8: lower chassis

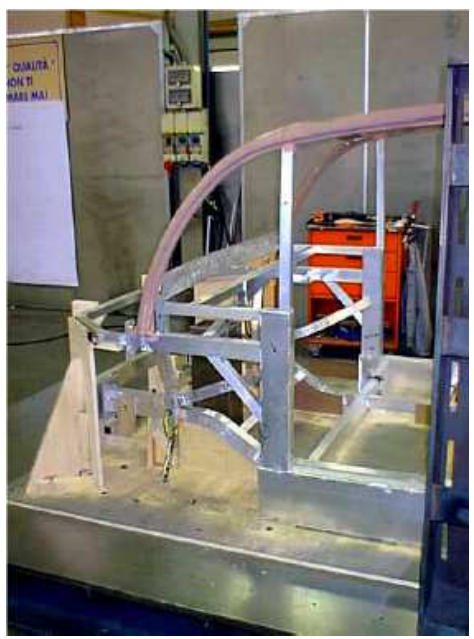

Figure 9: frontal chassis

One of the main characteristics of the chassis is the arrangement of the battery pack in a lower and protect position. The aluminum extrusions are used in replacement of longerons, which characterized the commercial vehicles at the moment. In this way it is possible to increase the available volume for the load in a vehicle with equal length and width.

The construction of the chassis was performed in two steps, the former is the planning and feasibility, the latter is the achievements and installation of the mechanical parts. The modularity of the different systems (chassis, powertrain, cabin, rear part) allow easy "body configurability" for different applications in the areas of freight-distribution. Modularity is the most important feature which allow to meet all the needs of the local transport of goods as it's possible to notice in Figure 10. 


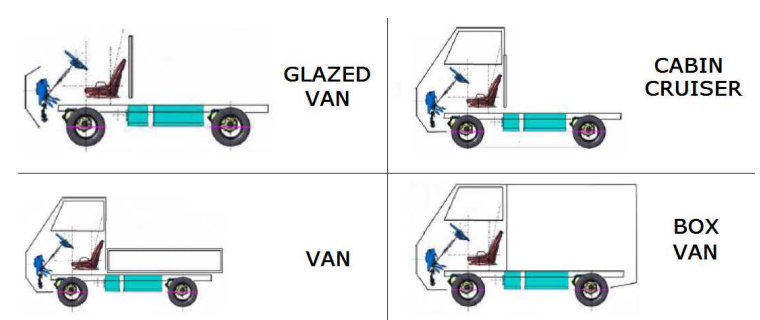

Figure 10: different upper body solutions

The study and design of different upper body outfitting has been done to achieve an innovative and attractive design as the large glazed surface that it allows better driving conditions. The design of the vehicle will have considerable importance because it aims to achieve a product appealing also from the purely aesthetic point of view. Subsequently integration between design and different upperbody solutions have been done. This integration is an important added value compared with the commercial vehicles of category $\mathrm{N} 1$ present on the marketplace. In the figure below an example of vehicle design.

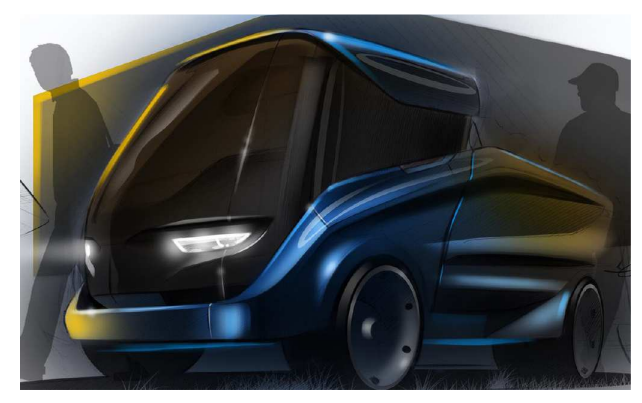

Figure 11: Design example

\subsection{Communication}

An info mobility system in order to collect, process and transmit the positioning and operational data of the vehicle to a service centre has been installed. It is able to also to interface with an environmental monitoring subsystem and transmit acquired data. The possibility to read driving operating parameters and warning/fault of the vehicle has been done by a tablet or smartphone. The info mobility system collect realtime vehicle data of operating and diagnostics parameters by using OBDII port. The logging data and the sending time to the service centre can be customized.

Before the sending the data are stored in a memory system and then they are sent to the service centre. This store and forward mechanism ensures high transmission reliability of data to the service centre also in unavailable connection cases. The communication will be done through GPRS or UMTS channel.

\section{Conclusion}

The development of a new concept of electric vehicle for last mile transportations is characterized by elements of higher technological innovation and design than vehicles currently on the market. It aims to achieve an attractive design that ensures, at the same time, easiness of use and comfort. The design of the rolling chassis guarantees flexibility and modularity of the vehicle. Such characteristics makes it suitable for different missions of use. The design of the cabin with the info mobility system and the larger glass surface than conventional commercial vehicles, favours greater manoeuvrability of the vehicle.

For freight transport, an important qualitative value is represented not only by the different types of upper body but for the mobile platform. This also facilitates the loading and unloading of goods. In order to reduce pollution in urban centres, the proposed vehicle has been carried out with electric powertrain. The use of the vehicle, as described, is part of a transport organization based on intermodality, one of the key elements of intelligent transport systems (ITS). The conclusion of the project involves in the construction of the vehicle for freight transport.

\section{References}

[1] European Commission, White paper, European Commission, 2011.

[2] Amna Bouhana, Habib Chabchoub, Mourad Abed, Afef Fekih, A Multi-Criteria Decision Making Approach Based On Fuzzy Theory and Fuzzy Preference Relations For Urban Distribution Centers' Location Selection Under Uncertain Environments, IEEE, 2013.

[3] Stephanus Daniel Handokoy, Duc Thien Nguyeny, and Hoong Chuin Lau, An Auction Mechanism for the Last-mile Deliveries via Urban Consolidation Centre, IEEE, 2014

[4] Stanisław Iwan, Kinga Kijewska, Dawid Kijewski, Possibilities of Applying Electrically Powered Vehicles in Urban Freight Transport, Elsevier, 2014

[5] G. Napoli, L. Andaloro, F. Sergi, N. Randazzo, V. Antonucci, Electric Vehicles for urban logistics improvement, , IEEE, 2014

[6] Lalit Kumar, Shailendra Jain, Electric propulsionsystemforelectricvehiculartechnology: Areview, Elsevier, 2013 


\section{Authors}

Laura Andaloro: Degree in Mechanical Engineering at University of Arcavacata (Cosenza, 2002) and Master in "Sistemi di produzione dell'idrogeno e mezzi di trasporto con celle a combustibile", University of Messina, 2008. Current position: Researcher at the Institute of Advanced Technologies for Energy "Nicola Giordano" of National Research Council of Italy (CNR ITAE) in MESSINA.

Dr. Giuseppe Napoli: Degree in Electronic Engineering. and $\mathrm{PhD}$ in "Tecnologie Avanzate per l'Ingegneria dell'Informazione" at University of Messina. Current position: Researcher at the CNR-ITAE of Messina performing activity on new technologies for electric and hybrid electric powertrain. The main activities concern the development of new system architectures and components for low emission vehicles and solutions for control and management of advanced subsystems.

Dr. Francesco Sergi: Degree in Electrical Engineering at the University of Pisa, Ph.D. in Materials for Environment and Energy at the University of Rome Tor Vergata. Current position: Researcher at the CNR-ITAE of Messina, performing research on fuel cells (FC) at low and high temperature (PEFC and SOFC), on energy storage technologies and on integration between new technologies and renewable energy sources.

Salvatore Micari: Degree in Electronic Engineering at Politecnico of Turin in 2010. He works at Italian National Research Council - Institute for Advanced Energy Technologies "Nicola Giordano" as an electronic engineer. His research activities include research, development and test of hybrid and electric vehicles for automotive applications.

Giuseppe Agnello: Degree in Electric Engineering at University of Palermo in 2013. He works at Italian National Research Council - Institute for Advanced Energy Technologies "Nicola Giordano" as an electric engineer. His research activities include research and test of electrochemical storage system.

Dr. Vincenzo Antonucci: Project leader Distributed Energy Systems of CNR, Dept Energy and Transportation and Research Manager of Energy Systems Project at CNR- ITAE, Former President of Commission CEI (Italy IEC section) WG 105 Fuel Cells, energy expert (Italian Ministery, European Commission,Regions), former Member of SRA and IP Working Group HFC Platform, Member Italian HFC Platform and Leader Deployment Group, Member of Management for the definition of Energy Plan for Sicily Region. 